\title{
DE ERWTENPLANT SCHRIJF- \& PAPIERDOOS VAN MORIYA SHŌTEI
}

In Europa ziet men graag Japanse kunst uit de Tokugawa- en de Meijiperiodes. De kunstuitingen zoals die tussen I60o en I9I2 tot stand kwamen worden beschouwd als 'typisch Japans'. Het overgrote deel van de Japanse kunst in Europese musea stamt dan ook uit deze periodes, terwijl zowel de vroegere als de latere periodes slechts fragmentarisch vertegenwoordigd zijn. Wanneer men bereid is de oogkleppen te verwijderen zal zich een nog veel rijkere schakering aan kunstvormen openbaren en de term 'typisch Japans' zal een nieuwe inhoud krijgen.

Dit alles geldt ook voor de Japanse lakkunst. In de jaren I930 schudde de lakkunst haar traditionele veren gedeeltelijk af. De opmerkelijke Erwtenplant schrijf- \& papierdoos van Miroya Shōtei (I890-I972), die dateert uit I930, kan hiervan als voorbeeld dienen.

\section{Ontwerp en laktechnieken}

De doos van Shōtei heeft de vorm van een kistje, waarvan de hoeken met metaal versterkt zijn (afb. I). Bij nauwkeuriger observatie valt op dat het kistje bestaat uit twee lagen, waarvan de onderste tweemaal zo hoog is als de bovenste. Het deksel van de bovenste laag is in tweeën gedeeld. De beide helften kunnen opengeklapt worden langs gemeenschappelijke scharnieren in het midden. Onder het deksel bevinden zich twee compartimenten. Het rechter compartiment bevat de gebruiksvoorwerpen van een schrijfdoos in Japanse stijl: een inktsteen, een waterdruppelaar en twee penselen (afb. 2). Het linker compartiment bevat de gebruiksvoorwerpen van een schrijfdoos in Westerse stijl: een rode en een zwarte kroontjespen, twee kleine inktpotten en een ivoren papiermes (afb. 3). De onderste laag bestaat uit slechts één compartiment, dat bedoeld is om schrijfpapier in te bewaren.

De gelaagde combinatie van een schrijfdoos met een papierdoos was ongewoon, maar niet uniek. Het beroemdste voorbeeld ervan is de schrijfdoos met een afbeelding van de 'achtvoudige brug' (yatsuhashi) van Ogata Kōrin (I658-I7I6), die op de Japanse lijst van nationale kunstschatten staat.

De combinatie van een schrijfdoos in Japanse stijl met een schrijfdoos in Westerse stijl was in 1930 echter nog nooit eerder vertoond. Mijns inziens moet deze combinatie niet zozeer worden gezien als een symbool voor de veranderende tijd (want die verandering was al ingezet in de jaren na de Meiji Restauratie van I868), maar veeleer als een karakteristiek van de jaren I920-I940, waarin Japanse en Westerse levensstijlen, in elk geval in de grote steden, naast elkaar bestonden.

Datzelfde samengaan van Westers en Japans treffen wij aan in de decoratie.

De buitenkant van het kistje is versierd metgestileerde voorstellingen ${ }_{023}$ 02:36:37pM 
Afb. 2

De schrijfdoos in Japanse stijl wordt zichtbaar na het openklappen van de rechterhelft van het deksel.

Foto: Rijksmuseum, Amsterdam

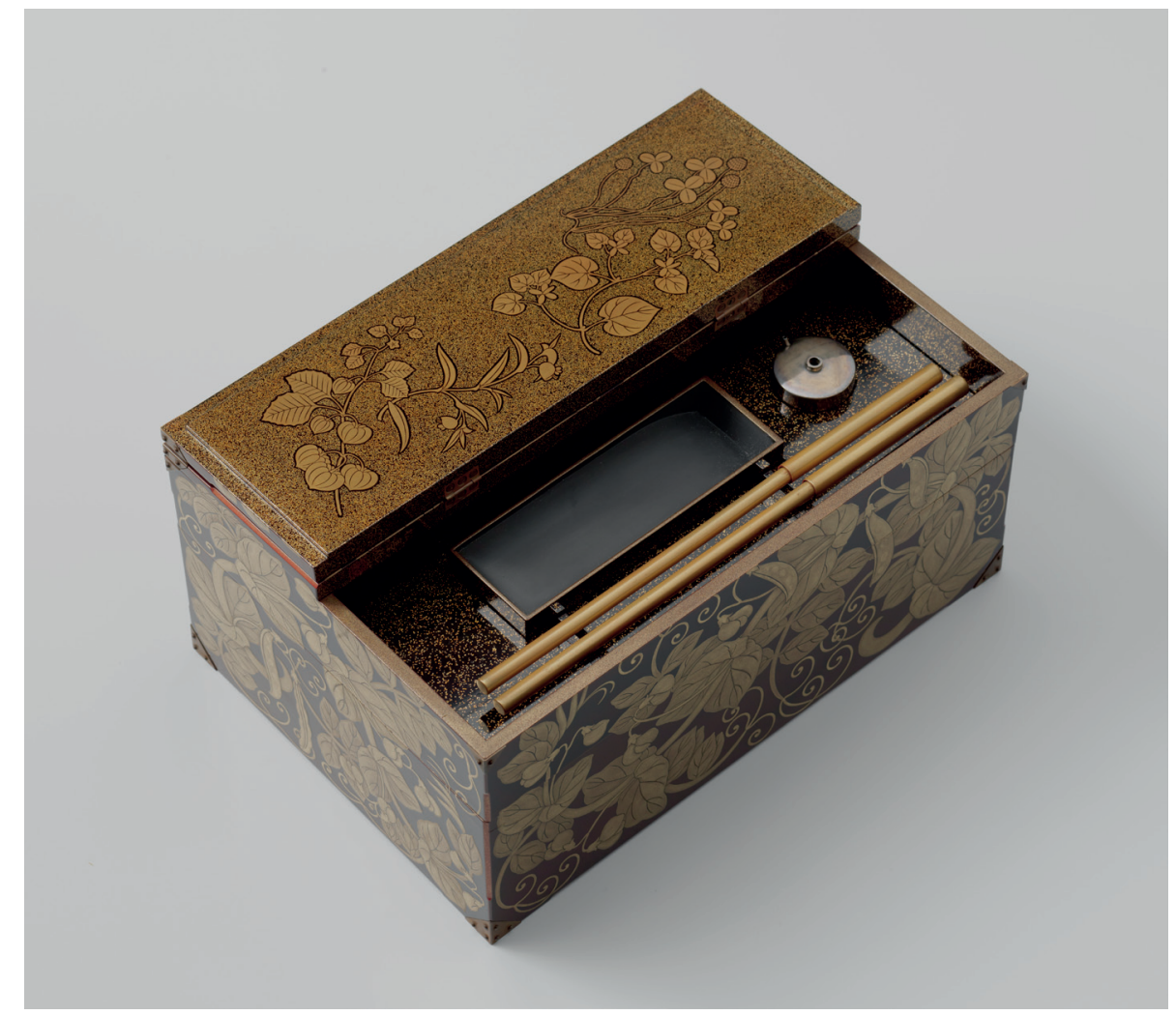

Afb. 3

De schrijfdoos in Westerse stijl wordt zichtbaar na het openklappen van de linkerhelft van het deksel.

Foto: Rijksmuseum, Amsterdam

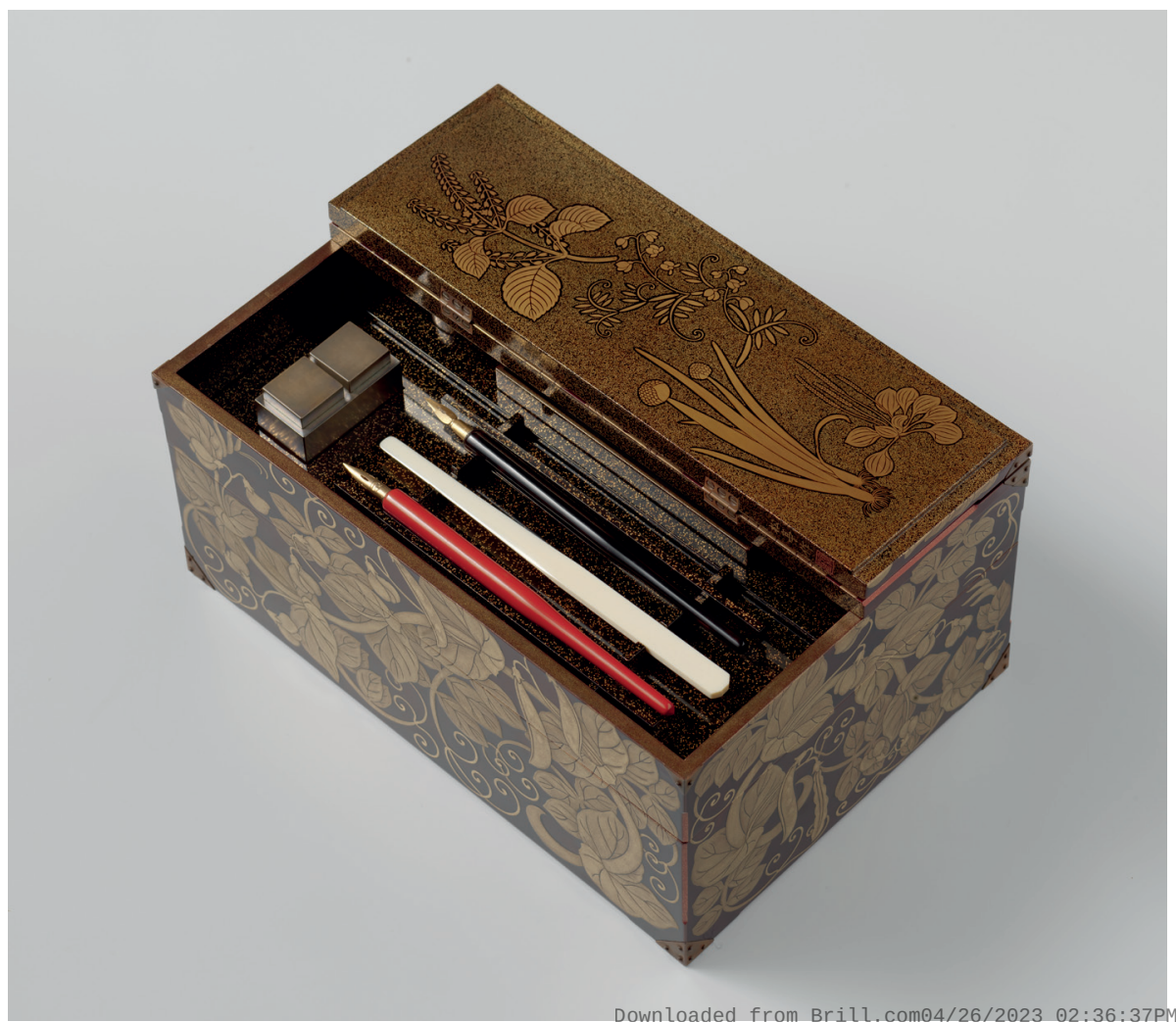


van de erwtenplant (Pisum sativum), inclusief de bijbehorende bloemen en peulen (afb. 4). Deze licht verheven goudlak decoratie (hiramakie) steekt af tegen de roodbruine ondergrond. De kanten zijn dunnetjes afgeschuind en voorzien van een contrasterende, fel oranjerode kleur waarop goudpoeder is gesprenkeld (shukin). Florale ranken komen zeker veelvuldig in de lakkunst voor, maar deze sierlijke erwtenplanten hebben toch een onmiskenbaar exotisch karakter. Dit geldt beslist niet voor de binnenkanten van de opklapbare deksels. Op elke binnenkant zien we vier gestileerde planten in een sublieme uitgeslepen togidashi techniek op een ondergrond die besprenkeld is met goudsnippers (afb. 2 en 3).

Het is verleidelijk om te veronderstellen dat het ontwerp van de buitenkant geïnspireerd is op een antieke boekspiegel gemaakt van goudleer, die in 1925 (dus vijf jaar voor de vervaardiging van de Erwtenplant schrijf- \& papierdoos) in de Tokyo Art Club werd geveild (afb. 6). Dergelijke Nederlandse boekspiegels dateren uit de $17^{\mathrm{e}}$ eeuw en werden door de VOC in Japan geïmporteerd. Naast de kleurstelling en het ontwerp van de krullende versiering pleiten voor deze inspiratiebron bovendien de wijze waarop de deksels openklappen (al doen ze dat andersom) en de bevestiging van de metalen hoekversterkingen met drie pennetjes (zoals bij de spiegel de scharnieren zijn vastgezet). Dergelijke inspiraties op kunstuitingen uit vreemde culturen waren in de jaren 1930 in Japan schering en inslag, in het bijzonder voor het werk dat gemaakt werd voor de prestigieuze nationale kunsttentoonstellingen. De Erwtenplant schrijf- \& papierdoos is vervaardigd voor de tentoonstelling van de Keizerlijke Academie voor de Kunsten in I930: de Teiten.

\section{Ontwerptekeningen}

Hoe brengt de lakmeester zijn getekende ontwerp eigenlijk over naar het object? Dat gebeurt door de lijnen van de tekening op dun papier aan de achterzijde met roodbruine lak te traceren. Als die bewerking is voltooid wordt de nog 'natte' achterkant op de gelakte ondergrond van het object gelegd en afgewreven. Zo ontstaat een dunne, roodbruine tekening op de al afgewerkte ondergrond en kan de opbouw van de lakdecoratie beginnen. Het gebeurt slechts zelden dat de ontwerptekeningen (shitae) van een object bewaard zijn gebleven. De verrassing was dan ook groot toen een bevriende verzamelaar uit Tokyo mij berichtte dat hij de tekeningen van de Erwtenplant schrijf- \& papierdoos had aangetroffen in een van de twee albums waarin Moriya Shōtei de ontwerptekeningen van heel zijn oeuvre had bewaard. Het bleek te gaan om drie tekeningen van de buitenkant: één voor het deksel (afb. 5), één voor de lange zijkanten en één voor de korte zijkanten. Daarnaast was er nog een tekening van de binnenkant van het deksel. Op de achterkant van deze tekeningen zijn de resten van de laktraceringen duidelijk zichtbaar (afb. 7). Het is boeiend om roodbruine lijnen te volgen en te zien waar deze de tekening nauwkeurig volgen, maar ook waar ze er soms corrigerend van afwijken of van afwijken om een krullende lijn net wat meer zwier te geven. Zo is het grote blad direct onder het onderste scharnier in het object kleiner uitgevallen om de scheut daarnaast meer ruimte te gunnen. Eerst had Shōtei in potlood al gepoogd om deze scheut wat naar boven te verplaatsen, maar daar heeft hij in laatste instantie toch van afgezien. Het ontwerpproces ging kennelijk tot op hest laatste mement ma $_{\text {o2:36:37pM }}$ 

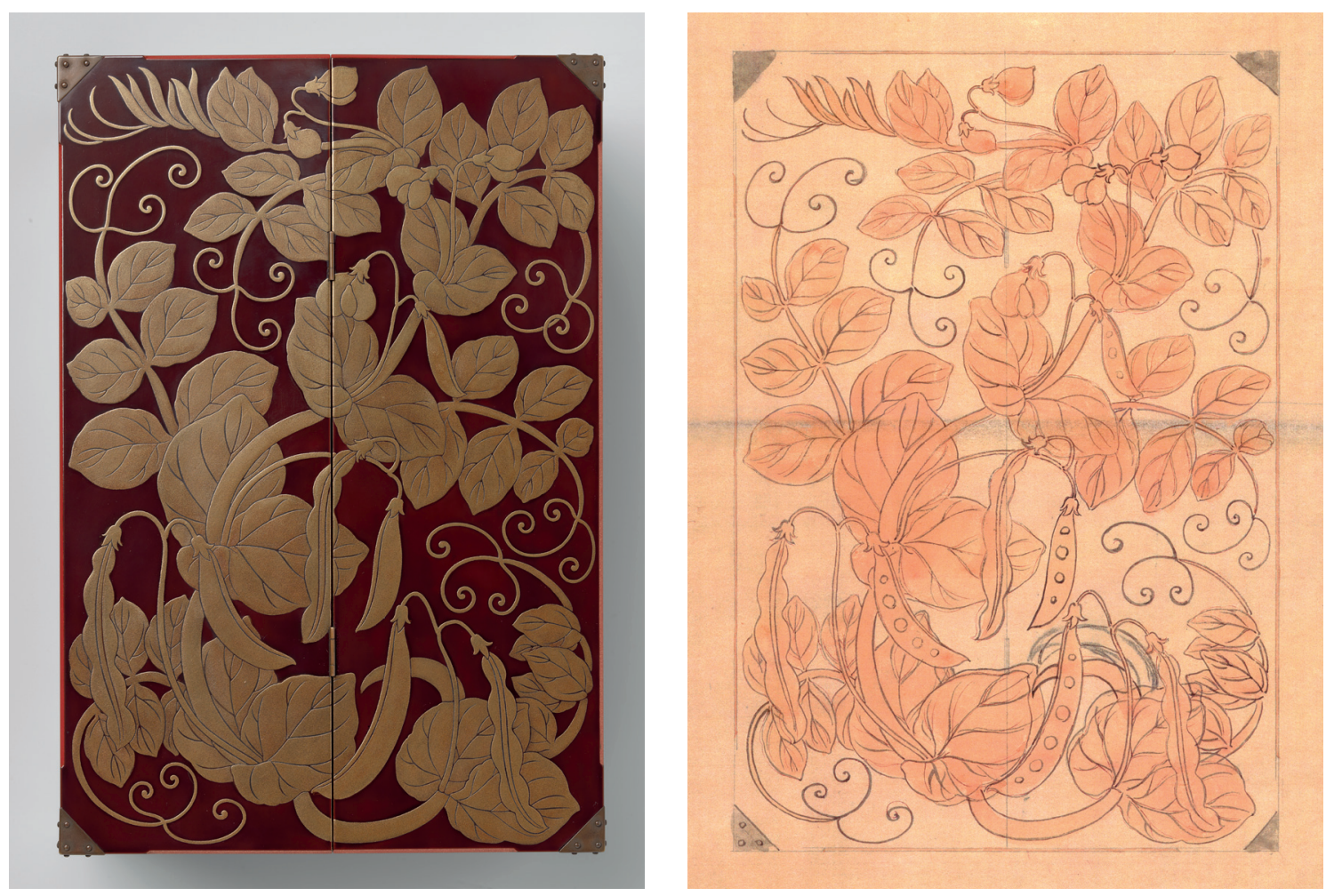

Afb. 4 (links)

Bovenaanzicht van het deksel, waarvan beide helften met scharnieren verbonden zijn. Foto: Rijksmuseum, Amsterdam

Afb. 5 (rechts) Ontwerptekening van het deksel, Yoshikawa collectie, Tokyo door en is niet gestopt bij de tekening. Zó dicht bij de lakmeester komt men niet vaak.

Een ander aspect van het ontwerpen wordt inzichtelijk doordat er van de binnenkant van het deksel nog een eerdere versie van de ontwerptekening in het album bleek te zitten (afb. 8). In dit stadium waren op beide dekselhelften nog vijf in plaats van vier planten te zien. Bovendien lijken deze planten net een stapje dichter bij de natuur te staan. Wellicht is dit het stadium halfweg de eerste schetsen en het gestileerde eindresultaat. Ontwerptekenen vereist immers wezenlijk andere vaardigheden dan tekenen naar de natuur.

\section{De kunstenaar}

Moriya Otosaburō, zoals hij toen nog heette, werd in I890 in Kyoto geboren. Als I7-jarige verhuisde hij naar Tokyo om als intern student in de leer te gaan bij Shirayama Shōsai (I853-I923), een van de grote namen uit die tijd. Tot zijn huwelijk in I920 bleef Shōtei daar wonen. Aanvankelijk kreeg hij allerhande huishoudelijke taken toegewezen, zoals het vegen van de vloeren in het atelier, en mocht hij slechts toekijken bij de lakbewerkingen. Geleidelijk aan breidden zijn taken zich uit, steeds onder strikte supervisie van de meester. Er is een briefje bewaard gebleven van Shōsai, die toen op reis was, aan zijn leerling Shōtei, waarin de meester hem instructies gaf op welke wijze hij de ogen van twee Chinese leeuwen moest polijsten om deze de indringende uitdrukking van kabuki-acteurs te geven. Tevens ontving hij van zijn leermeester systematisch onderricht in kunstgeschiedenis. 
Afb. 6

Boekspiegel van

goudleer, 35 × 30,5

$x 2 \mathrm{~cm}$., Nederland,

$17^{\mathrm{e}}$ eeuw, Collectie

Inohana, Tokyo

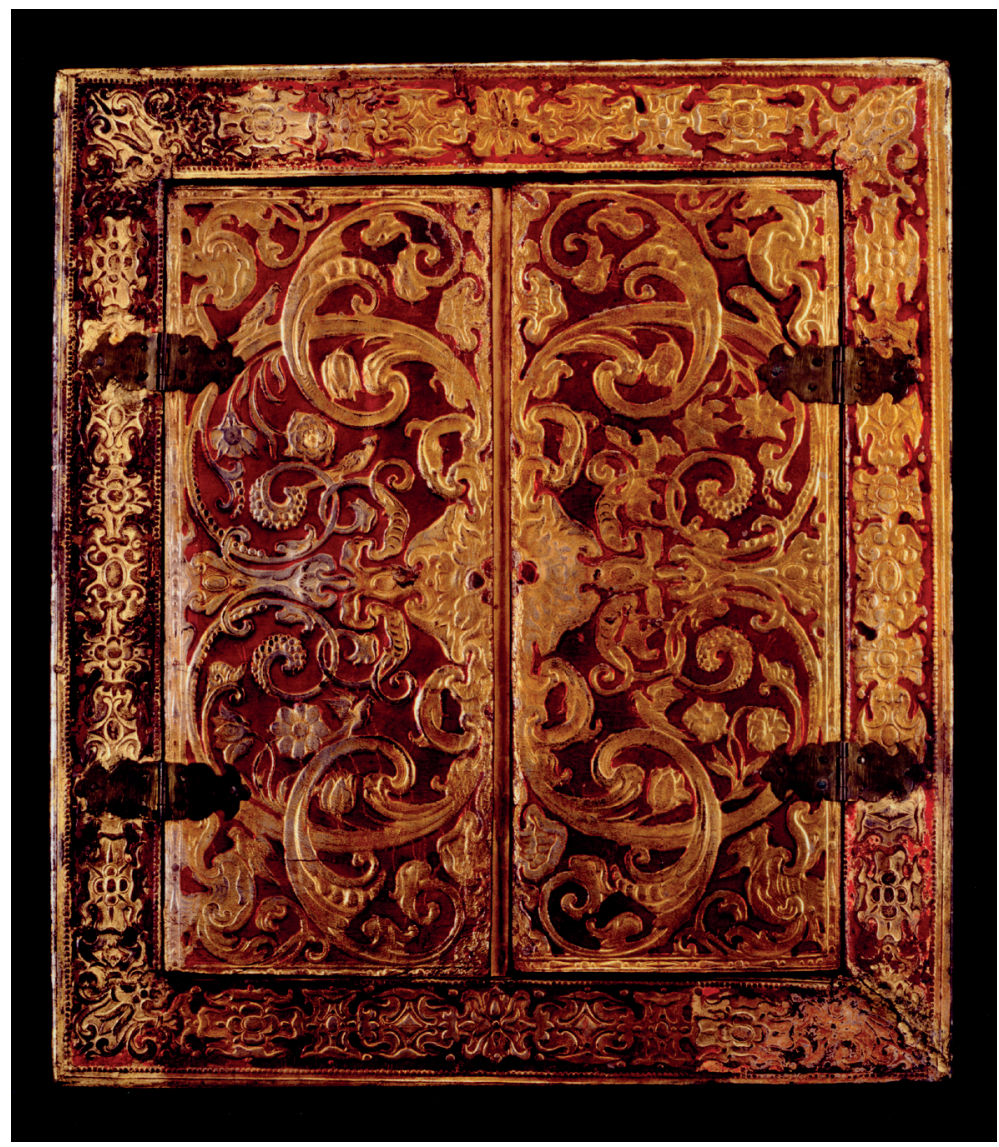

Afb. 7

Detail van afb. 5

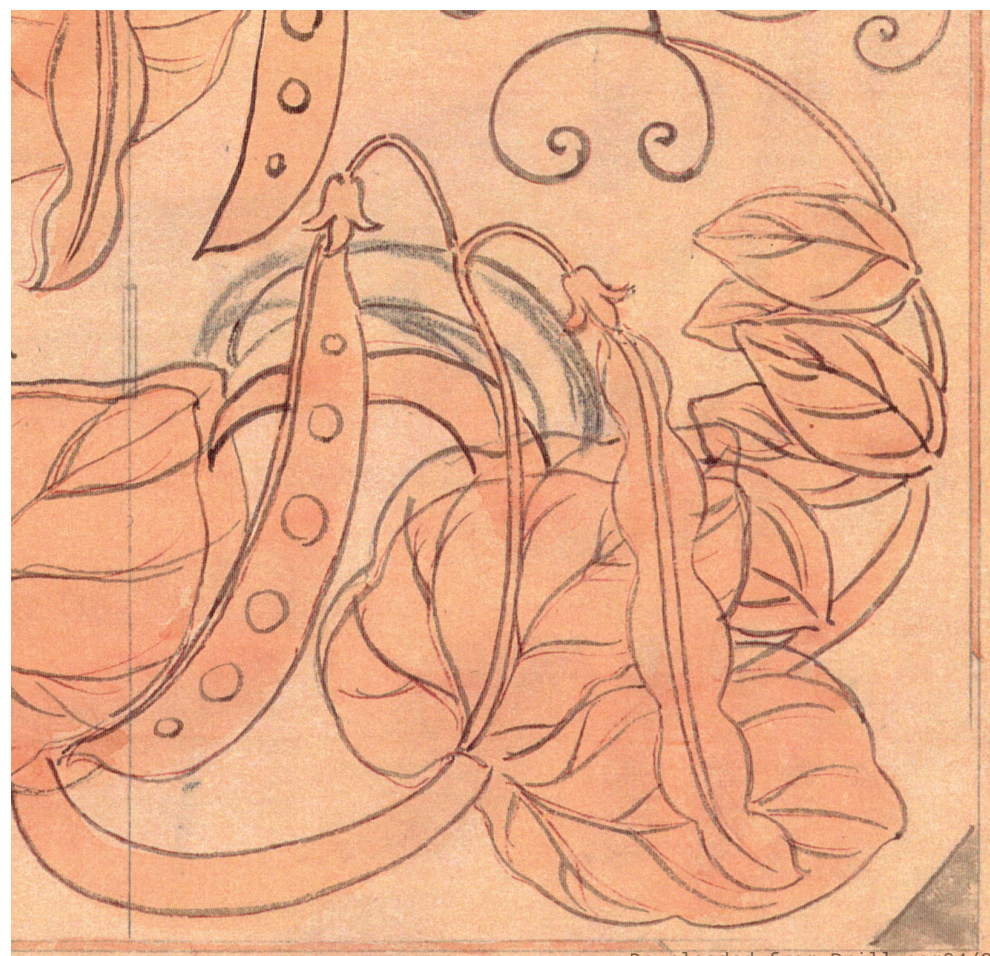


Afb. 8

Twee stadia van de ontwerptekeningen voor de binnenkant van het deksel,

Yoshikawa collectie,

Tokyo

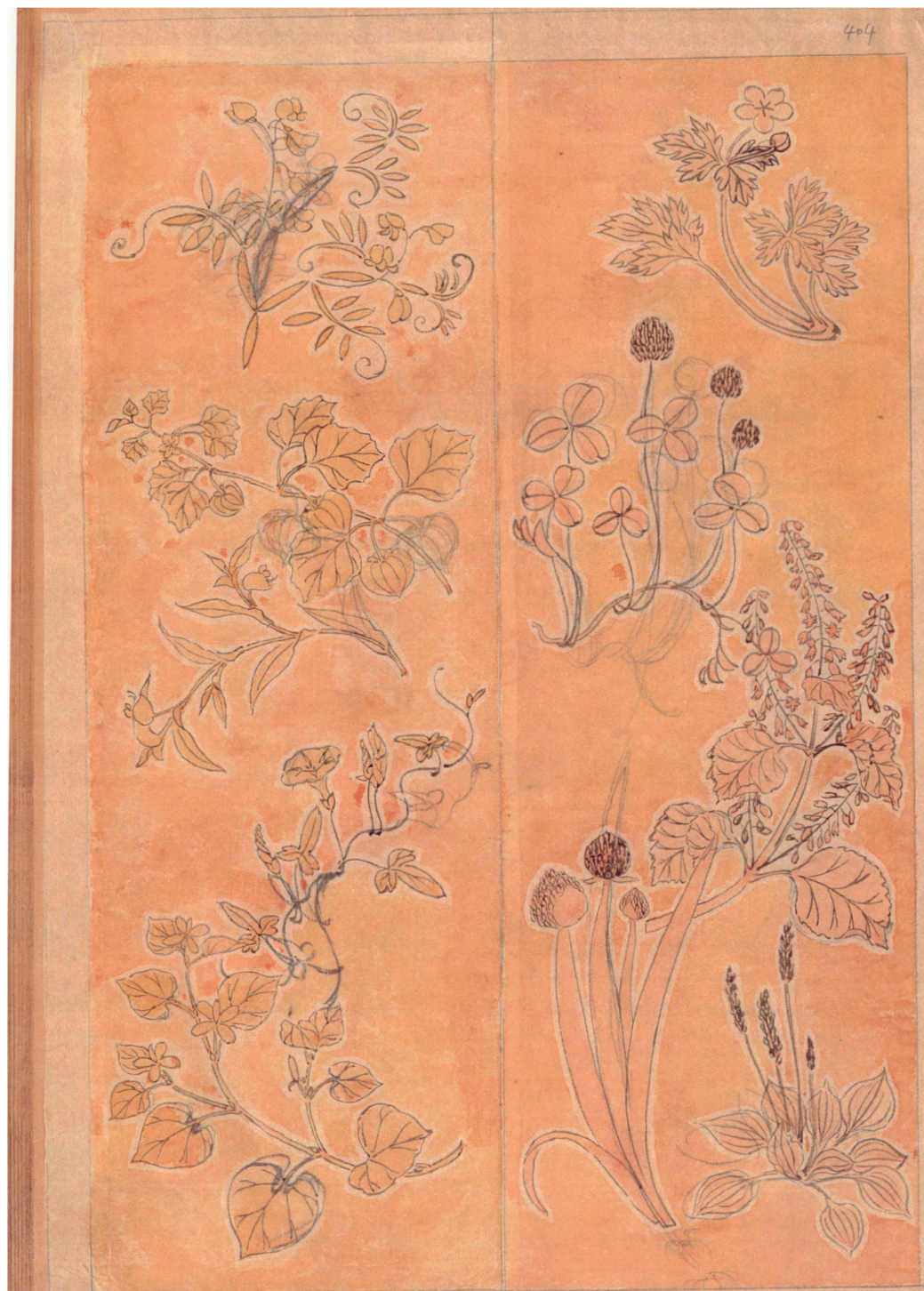

Waarschijnlijk heeft Shōtei zich pas na het overlijden van Shōsai in 1923 als onafhankelijk kunstenaar gevestigd. Tevoren had de meester hem zijn kunstenaarsnaam Shōtei met het eerste karakter uit diens naam toegekend. Net als vele andere lakkunstenaars met een tamelijk traditionele scholing werd Shōtei meegezogen in de golf van moderniteit die in het midden van de jaren 1920 de toegepaste kunstvormen in beweging bracht. De Erwtenplant schrijf- \& papierdoos hoort tot zijn belangrijkste werken uit deze periode. Vanaf 1942 is Shōtei zich gaan toeleggen op het maken van voorwerpen die gebruikt worden bij de theeceremonie. Naar men zegt gebeurde dit uit teleurstelling over gebrek aan waardering voor zijn kamerscherm De zeven geuren op een van de prestigieuze tentoonstellingen; hij nam er nooit meer aan deel. In zijn loopbaan won uiteindelijk de traditie, hoewel Shōtei's boeiendste werk ongetwijfeld dateert uit de jaren I930 en het begin van de jaren I940. 


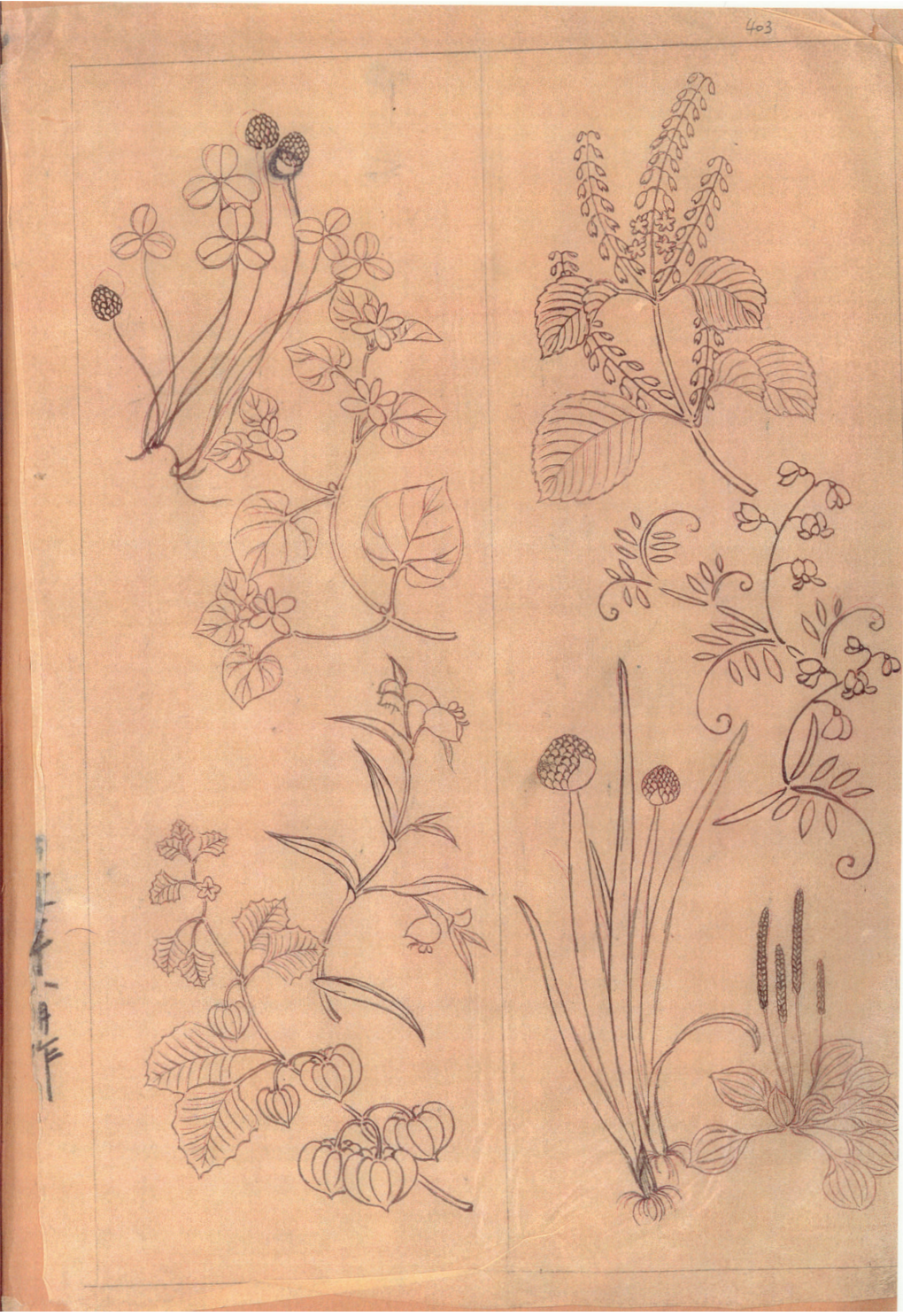

- In 1975 is Jan Dees geboeid geraakt door de lakkunst van Japan. Naast zijn werk als gastro-enteroloog verricht hij sinds de late jaren 80 in Europa en Japan onderzoek naar lakkunstenaars uit de periode I890-1950. Hieruit is in 2007 het proefschrift Facing Modern Times: The revival of Japanese lacquer art I890-1950 voortgekomen.

- De Erwtenplant schrijf- \& papierdoos is momenteel te zien op de tentoonstelling Japan Modern. Collectie Elise Wessels in het Rijksmuseum.

\section{LITERATUUR}

Hideki Yoshikawa, 'Biographical data concerning two makie masters: Toyohira Suisen from Okinawa and Moriya Shōtei from Kyoto' (Japanese text), Bulletin of Urasoe Art Museum, no.I2 (2003), pp. 79-89. 